“Transfer” XV: 1-2 (2020), pp. 191-206. ISSN: 1886-554

\title{
EDITORIAL PATASDEPEIXE: BREVE ANÁLISIS DEL CATÁLOGO Y POLÍTICAS DE EDICIÓN Y TRADUCCIÓN DESDE UNA PERSPECTIVA FEMINISTA.
}

Laura Sáez Fernández (ORCID: 0000-0001-6753-0469) Editora y directora de Patasdepeixe Editora

\section{Introducción}

Patasdepeixe arranca su actividad en el mes de septiembre de 2008 con la publicación de $O$ incrible neno devorador de libros, un álbum ilustrado de Oliver Jeffers. Esta editorial surge como un proyecto individual, resultado de un proceso de dos años de formación y reflexión en el que se combinaron estudios y prácticas editoriales.

Por una parte, hubo una reflexión teórica basada en el ya desaparecido Máster en Edición de la Universidad de Santiago de Compostela, y del DEA en la Universidad de Vigo, obtenido con el ensayo Estudo da viabilidade dun proxecto de creación dunha editora de traducións ao galego para público infantil, combinada con una labor profesional de traducción literaria para numerosas editoriales gallegas y estatales que comenzó en 2002. De esta forma, la práctica en empresas reales y reflexiones teóricas sobre la profesión provocaron en mí la necesidad de crear una editorial diferente que atendiese a necesidades creativas personales y del sector en aquel momento.

Patasdepeixe inicia así su catálogo con tres premisas fundacionales: Sería una editorial que publicaría textos traducidos, publicaría sólo en lengua gallega y se declararía totalmente independiente en el ámbito económico, es decir, se mantendría en el 
“Transfer” XV: 1-2 (2020), pp. 191-206. ISSN: 1886-554

mercado solo por ventas de libros, y nunca con subvenciones del gobierno gallego. ${ }^{1}$

Siguiendo estas tres líneas, Patasdepeixe llega hasta 2019 con un catálogo de veintiún títulos publicados, ${ }^{2}$ con una tirada media de 1000 ejemplares por impresión. Sigue siendo hasta la fecha un proyecto unipersonal y totalmente independiente.

Durante estos años nunca ha habido una planificación previa del catálogo, pues los títulos publicados se han decidido por elección puntual de proyectos, y no como resultado de una política editorial concreta. Sin embargo, dado el volumen actual de títulos, ahora podemos hacer un análisis de dicho catálogo bajo distintas perspectivas, como por ejemplo los formatos y las autorías.

\section{El formato}

Debido a la coincidencia temporal de la creación de la editorial con la época de esplendor del álbum ilustrado, el sello se ha centrado únicamente en este formato/género. Aunque la naturaleza del álbum ilustrado y las grandes posibilidades que este formato/ géne-ro proporciona a lectoras/es, creadoras/es e incluso traductoras/es (Sezzi 2008) no sea objeto de este artículo, analizaremos brevemente diferentes definiciones de este formato/ género, pues las necesitaremos posteriormente para centrarnos en la perspectiva feminista de nuestro catálogo.

\footnotetext{
${ }^{1}$ Las motivaciones para esta idea de autosuficiencia no son relevantes para este artículo, pues nos centraremos en el género y no en políticas lingüísticas, pero se pueden consultar en el propio trabajo de DEA en la Universidad de Vigo Estudo da viabilidade dun proxecto de creación dunha editora de traducións ao galego para público infantil (año de defensa 2007).

2 En realidad, la editorial cuenta con veintidós títulos, pero O libro dos opostos está agotado y no hay posibilidad de reedición, así que para este estudio nos centraremos solo en el catálogo vivo de la editorial.
} 
“Transfer” XV: 1-2 (2020), pp. 191-206. ISSN: 1886-554

El concepto "álbum ilustrado" es relativamente nuevo. Según el periodista Jorge Morla (2015), citando al editor de Libros del Zorro Rojo, Samuel Alonso, este concepto fue acuñado por primera vez en España en 1997 en Salamanca, en un acto de la Fundación Germán Sánchez Ruipérez. Según Morla:

[...] no son libros para niños ni novelas gráficas, son relatos cosidos con ilustraciones. Ediciones cuidadas al máximo en las que la lectura es acompañada, guiada, por ilustradores que, lejos de limitarse a adornar un texto, lo complementan, mientras van ganando su propio espacio como creadores". (Morla, El País $31 / 07 / 2015)$

Es importante en esta definición periodística subrayar que el álbum ilustrado no es un producto exclusivamente para niñas/os, así como indicar el importante peso de las ilustraciones en todo el libro.

En cuanto a su naturaleza única y diferenciada de otro tipo de libro ilustrado o de texto con ilustraciones, la especialista en literatura infantil Maria Nikolajeva especifica:

The unique character of picturebooks as an art form is based on the combination of two levels of communication, the visual and the verbal $[\ldots]$ The tension between these two functions creates unlimited possibilities for interaction between word and image in a picturebook. (Nikolajeva 2006: 1)

Así, en el álbum ilustrado se crea además un tercer nivel comunicativo que es el creado por la interacción imagen-palabra, o en palabras de Barbara Bader, un "diseño total":

Un álbum es texto, ilustraciones, diseño total; una pieza fabricada y un producto comercial; un documento social, cultural e histórico y, sobre todo, una experiencia para el niño. Como forma de arte, gira en torno a la interdependencia de imágenes y palabras, al juego simultáneo de dos páginas enfrentadas y a la emoción 
“Transfer” XV: 1-2 (2020), pp. 191-206. ISSN: 1886-554

que supone pasar la página. (Bader 2012: 75, citada en Salisbury \& Styles 2012)

En conclusión, se trata de libros que se leen en tres niveles diferentes (texto, imagen y texto-imagen), objetos que se observan y se manipulan, textos que pueden estar diseñados para todas las edades y un producto cultural e histórico actual.

\section{La autoría}

El álbum ilustrado tiene dos autorías primarias: autora/ilustradora y varias autorías secundarias: maquetadora/editora/traductora. Del conjunto de todas estas funciones surge el libro-objeto que definimos antes, donde todas las decisiones, desde el texto y la ilustración, hasta el tipo de papel escogido conforman el producto final y son igual de relevantes.

Si hacemos un estudio de las autorías, el catálogo de Patasdepeixe se podría clasificar de la manera siguiente:

1) Autorías primarias:

-Autoras-ilustradoras: Oliver Jeffers, Benoit Jacques, Emily Gravett, Zdeněk Miller y Jan Pieńkowsky.

-Autoras/es: Andy Cutbill, Alexis Deacon, Julia Donaldson.

-Ilustradoras/es: Russell Ayto, Viviane Schwarz, Axel Scheffler, Sam Winston.

2) Autorías secundarias:

-Maquetación y diseño: Diego Núñez, Marcelino V. Cageao Ana Buján

-Traducción: Laura Sáez, Saleta Fernández, Jana Vavřinova, 
“Transfer” XV: 1-2 (2020), pp. 191-206. ISSN: 1886-554

-Edición: Laura Sáez.

\section{Análisis del catálogo desde una perspectiva feminista ${ }^{3}$}

Como explicamos antes, el catálogo de la editorial nunca siguió una política editorial predeterminada, sino que las elecciones de títulos se basaron siempre en la aparición de proyectos específicos en el momento adecuado. Sin embargo, al fijarnos en el anterior análisis de autorías nos sorprende el resultado si nos fijamos en el reparto de géneros y roles.

Como podemos ver, los autores primarios son principalmente hombres (nueve autores/ilustradores frente a tres autoras/ ilustradoras), mientras que las autorías secundarias (traducción, maquetación y edición) son principalmente femeninas (cinco traductoras, una editora y dos maquetadores).

Por una parte, se podría interpretar como un reparto meramente casual, pues siempre fueron exclusivamente los textos, independientemente de autor/a e ilustrador/a, los responsables de su publicación, y la editora nunca se preocupó por el género de su autora/autor o ilustradora/ilustrador.

Sin embargo, se podría hacer también una lectura no casual de los repartos de dichas autorías, que coincidiría con una lectura

\footnotetext{
${ }^{3}$ Utilizamos el término "feminista" y no "de género" expresamente, porque compartimos la preocupación de Lourdes Méndez: "En el actual contexto sociopolítico, una pregunta que puede formularse es la de por qué ciertos organismos internacionales solicitan investigaciones realizadas desde la "perspectiva de género" y nunca demandan estudios llevados a cabo desde "perspectivas feministas". ¿Por qué las consideran equivalentes o, al contrario, por qué saben que no lo son? Es cierto que existen teorías de género que son feministas y otras que no lo son, pero lo preocupante es que la voz feminismo haya desaparecido como por arte de magia del panorama político..." (Méndez 2007: 235-236, citado en Pena Presas 2018:14).
} 
“Transfer” XV: 1-2 (2020), pp. 191-206. ISSN: 1886-554

feminista mucho más amplia que abarcaría un problema sistémico que afecta a todo el sector editorial gallego.

El 14 y 15 de junio de 2018, se celebró en la Fundación Luís Seoane el encuentro Galeusca, organizado por la AGE, Asociación de Editoras Galegas, que se centraba en la igualdad de "género" en el sector editorial gallego.

El primer día se habló del sector editorial en general, políticas e internacionalización. En esta jornada, de mañana y tarde, intervinieron trece ponentes, y sólo tres de ellos eran mujeres. Sin embargo, el segundo día, en una jornada solo de mañana, participaron cuatro ponentes mujeres para hablar exclusivamente de la igualdad en el sector editorial. La jornada acabó con una exposición sobre la igualdad en el sector.

Para el encuentro, Belén López Vázquez, directora de Baía Edicións, y una de las ponentes de la segunda jornada, hizo un estudio en el que analizaba el reparto de puestos de trabajo en las editoriales gallegas en función del género. Los resultados, que se presentaron en dichas jornadas, aunque no se divulgaron después, indicaban que, en el sector editorial, las trabajadoras del sector constituían el $70 \%$ y las directivas, el 30\%.

Un análisis desde un punto de vista feminista del programa de las jornadas nos proporciona un ejemplo claro de las consecuencias reales que tienen estos datos abrumadores de repartos de género en el sector. Para tratar los temas clave del sector industrial, sus fortalezas y debilidades la AGE invitó a presidentes

\footnotetext{
${ }^{4}$ Véase nota 7.

${ }^{5}$ Según la página web de la Fundación Luís Seoane: "Organizado por la Asociación Galega de Editoras, el encuentro GALEUSCA reunirá durante 3 días a un grupo de especialistas y promotores del mundo de la edición en los territorios Galeusca con el fin de establecer una colaboración entre los gremios, compartir experiencias, estrategias y dar visibilidad a la edición en las lenguas propias. La situación editorial, el fomento de la lectura, la internacionalización del sector, la igualdad de género y la presencia de la mujer en el ámbito de la edición son algunos de los temas que se tratarán durante estas jornadas, que finalizarán el viernes 15 de junio en la Fundación Luís Seoane con la celebración de la exposición A igualdade de xénero no sector editorial galego" (2018).
} 
“Transfer” XV: 1-2 (2020), pp. 191-206. ISSN: 1886-554

de asociaciones de editoras y directores de editoriales (todos hombres), mientras que el segundo día, para tratar el tema de igualdad, invitó sólo ponentes mujeres, como si este tema afectase sólo al treinta por ciento del sector.

Este mismo problema estructural de desequilibrio de los repartos de tareas en el sector editorial por géneros lo podemos observar en la propia página web de la AGE. Un rápido estudio de las editoriales gallegas que pertenecen a la asociación y de sus páginas web nos permiten obtener la siguiente información: de las 37 editoras asociadas, 23 están dirigidas por hombres, 7 por mujeres y 7 no ofrecen esta información. Por el contrario, en la página web de AGPTI, la Asociación Gallega de Profesionales de la Traducción e Interpretación, vemos que, de las 83 asociadas, sólo 25 son hombres. Estos datos, aunque muy imprecisos y poco científicos, nos dan una idea de los repartos de trabajos en el sector editorial gallego $0^{6}$.

Aunque a nivel estructural, Patasdepeixe es una editorial que no sigue estos patrones machistas sistémicos que apuntaba Belén López Vázquez, pues a efectos estadísticos los cargos de

\footnotetext{
${ }^{6}$ El estudio de Belén López, que no es un estudio exhaustivo ni está publicado, muestra los siguientes datos: En las editoriales que pertenecen a la Asociación Galega de Editoras, las trabajadoras ocupan el $64,07 \%$ de los puestos de trabajo, mientras que solo el $27,83 \%$ de mujeres ocupan cargos directivos. La misma asociación, en 35 años de funcionamiento tuvo un $11,1 \%$ de presidentas, un $88,8 \%$ de presidentes, y sólo un 37\% de mujeres en cargos directivos. La misma tendencia se aprecia en la AELG, la Asociación de Escritores en Lingua Galega, donde un 70\% de los asociados son hombres y un 30\% mujeres.

Tan solo cambia un poco la dirección de estos datos en el caso de AGPTI, la Asociación Galega de Profesionais de Tradución e Interpretación, donde hay un 73\% de mujeres asociadas, y un $85,71 \%$ de mujeres en la directiva.

También las editoras independientes de nueva aparición en el paisaje editorial tienen una naturaleza más feminizada, más consonante con los datos de lectura y de compra de libros, donde un $64 \%$ recae en las mujeres y un $54,4 \%$ en hombres.

Este estudio de Belén López es extremadamente interesante y marca líneas de investigación que deberían ser cubiertas, pues su estudio exhaustivo podría establecer líneas de mejora claras y necesarias para el sector.
} 
“Transfer” XV: 1-2 (2020), pp. 191-206. ISSN: 1886-554

dirección, edición y administración recaen un 100\% en mujeres (en realidad, en la misma mujer), vemos que el catálogo no sigue este mismo patrón.

De acuerdo con el anterior análisis, mientras que las autorías principales recaen un $70 \%$ en hombres, las secundarias recaen un $70 \%$ en mujeres. Es este un trabajo de mejora pendiente para esta editorial.

\section{Análisis feminista de los contenidos del catálogo}

En sus primeros años de existencia, la política editorial de Patasdepeixe se centró más en aspectos administrativos, funcionales y artísticos, que abarcaban desde escoger un software de facturación hasta decidir el gramaje de papel perfecto para este o aquel libro, pasando por buscar alquileres para oficinas o hacerse un hueco en las librerías del país. Esta primera fase de desarrollo de una editorial es tan apasionante como caótica y en ella hay poco material, tiempo y espacio para analizar en profundidad la verdadera dimensión de las implicaciones de un libro concreto.

Sin embargo, es después, al tener tres o cuatro títulos en circulación, cuando empezamos a darnos cuenta de la vida de cada título y de su impacto real en la sociedad. En cada feria las familias comentan como se recibe un libro en cada casa, cuando visitamos una librería podemos ver las actividades de animación alrededor de un título o el efecto que tiene cada relato sobre la audiencia en las contadas de cuentos. Es en estos casos cuando una editora se da cuenta del efecto que causan las historias en cada lector/a y de la importancia que tienen los personajes que nosotros creamos como ejemplos de vida.

Fue a partir de este momento cuando nos dimos cuenta de la importancia crucial de ofrecer textos con una perspectiva feminista, importancia que fue creciendo hasta convertirse en un filtro de selección de textos fundamental para que un libro pudiese ser publicado en nuestra editorial. 
“Transfer” XV: 1-2 (2020), pp. 191-206. ISSN: 1886-554

Como explicamos antes, aunque el álbum ilustrado no es un producto diseñado exclusivamente para niños, existe el hábito de asociar este formato-género a las prelectoras, primeras lectoras y niñas y niños mayores. Es por ello que consideramos de importancia capital asumir la responsabilidad que las editoriales de material para la infancia tenemos a la hora de replicar o combatir ciertos roles de género.

Al visitar las ferias más importantes del sector, la feria de Frankfurt y en especial, la feria del libro de Bolonia, y al analizar los catálogos de muchas editoriales, creemos que existe una excesiva asignación de roles en los títulos destinados a la primera infancia. Aunque esta afirmación requiere un estudio mucho más riguroso, nuestra intuición y experiencia nos indica que hay una serie de asociaciones animal/objeto-género que aún no se cuestionan en el sector editorial.

Si nos centramos en libros de prelectoras, donde impera la dualidad dibujo-palabra existen infinitos clichés de género que, de tan abundantes, pasan desapercibidos. A modo de ejemplo, en la temática de la granja, hay ciertos animales que siempre son femeninos/hembras (la vaca, la gallina, la mariquita, la oveja) y otros que siempre son masculinos (el caballo, el cerdo, el ganso, el ratón), al leer libros sobre la selva, vemos que los animales salvajes suelen ser masculinos/machos: el león, la pantera, el camaleón... Del mismo modo, los medios de transporte, al personificarlos, siempre son masculinos y tienen nombre de chico: el barco, el tren. Estos roles son más obvios en el caso de mostrar ciertos oficios que casi siempre se presentan como masculinos: el pirata, el granjero, el médico, y oficios que siempre se presentan como femeninos: la profesora, la enfermera... la lista podría seguir hasta el infinito.

Aunque parezca ridículo, pocos libros para prelectoras pasan un tamiz feminista. Antes o después aparece un tópico de género, como una mamá paseando un carrito, una niña jugando con un peluche, etc., lo que, en nuestro caso, hace imposible su publicación. 
“Transfer” XV: 1-2 (2020), pp. 191-206. ISSN: 1886-554

En el caso de nuestro O libro dos Opostos, nuestro tercer libro en catálogo, había una ilustración de una casa a la que se le abrían y cerraban las puertas y en ellas se podía leer "Aberto" y "Pechado". En aquel momento, no habíamos reflexionado mucho sobre el concepto de género, y el libro era tan diferente y moderno para la primera infancia que decidimos publicarlo. Sin embargo, al abrir la puerta de la casita, había una foto de una niña sonriente con un vestido rosa que hoy en día no habría encajado en nuestra política de publicaciones.

A continuación, vamos a exponer algunos casos de títulos relacionados con nuestro catálogo que en su momento hicieron que nos cuestionásemos la necesidad de manipular textos, ilustraciones, o la (im)posibilidad de su publicación debido a aspectos de género:

\section{SOS TV, un libro que no pudimos publicar}

Como vimos antes, el álbum ilustrado se compone de dos partes interdependientes, el texto y la imagen. Por ello, a la hora de aplicar un filtro feminista a nuestro catálogo, la tarea se duplica en complejidad, pues hay textos o, más bien, argumentos que nos gustaría publicar, y, sin embargo, la ilustración lo hace imposible. Este fue el caso del libro SOS Television, editado en castellano por la editorial Ekaré.

Este libro trata de una familia a la que una tarde, se les estropea la televisión, y después de unos momentos iniciales de pánico, se dan cuenta de que su propia compañía es el mejor de los entretenimientos. Aunque el argumento es genial y el texto es realmente divertido y original, las ilustraciones, que también son desternillantes y de calidad impecable, replican ciertos roles de género de otra época.

Con mucho pesar, pues la calidad de la ilustración y del texto eran exquisitas, decidimos no publicar este libro, pues, aunque pasase todo criterio de calidad, no encajaba con nuestro proyecto. 
“Transfer” XV: 1-2 (2020), pp. 191-206. ISSN: 1886-554

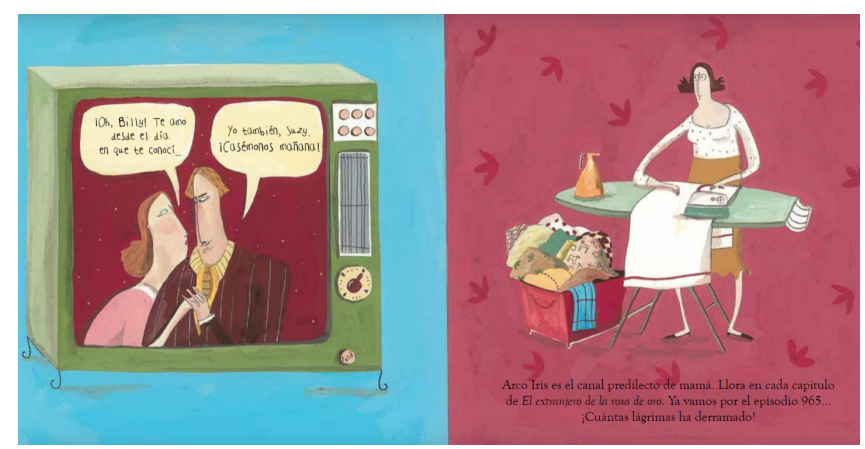

2. The Cow that Laid an Egg, un libro que decidimos manipular A veces, recurrimos a estrategias poco éticas con el original, pues si el libro nos gusta muchísimo y detectamos roles de género que no compartimos pero que podemos manipular en la traducción (siempre respetando el trabajo de autoras e ilustradoras), intentamos hacerlo. Este es el caso de First Week in Cow School/Primeira semana na escola de vacas. En este caso, el texto e ilustraciones son de calidad intachable, originales y muy graciosas. Además, el libro trata del concepto de integración y diversidad. Sin embargo, la protagonista es una vaca y una vaca la profesora (dos clichés de género abundantísimos en la literatura infantil), en una parte del texto incluso se habla de las vacas pequeñas que van a la escuela y de las madres vacas llorando al dejar a sus niños en la escuela.

En este caso, decidimos añadir algunos toques "igualitarios" al texto, como, por ejemplo: "las vacas y los toros lloraban al dejar a sus crías en la escuela", consiguiendo así un texto más inclusivo que el original, sin modificarlo sustancialmente, para que los autores aceptasen dichos cambios, y así poder incluir este libro maravilloso en nuestro catálogo. 
“Transfer” XV: 1-2 (2020), pp. 191-206. ISSN: 1886-554

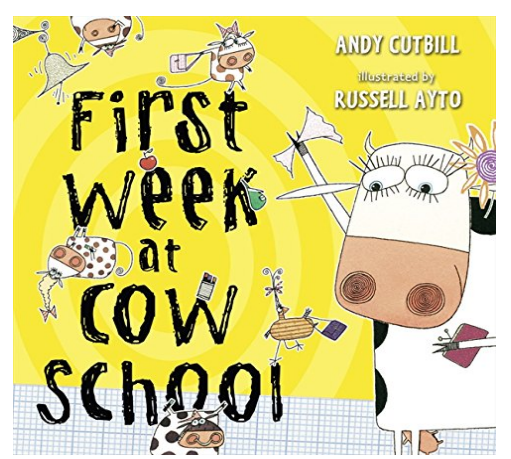

3. The Gruffalo, un libro de género cambiante

En la literatura infantil, por lo general, los monstruos son siempre masculinos. Es por esta atribución de género generalmente aceptada que cuando aparece un monstruo femenino, se le atribuya género masculino por defecto. Este fue el caso de The Grufalo's Child. Como la hija de esta criatura no tiene lazos, ni vestido, ni muñecas, ni es rosa, ni es buena ni sumisa, y dada la neutralidad de la palabra "child" y la ausencia del pronombre "she" en todo texto, en muchas ediciones se asumió que el pobre bicho era masculino. Sin embargo, la autora la concibió desde el comienzo como una niña aventurera que se escapa de su padre en medio de la noche.

En la imagen se pueden ver las ediciones española, gallega y portuguesa. 
“Transfer” XV: 1-2 (2020), pp. 191-206. ISSN: 1886-554
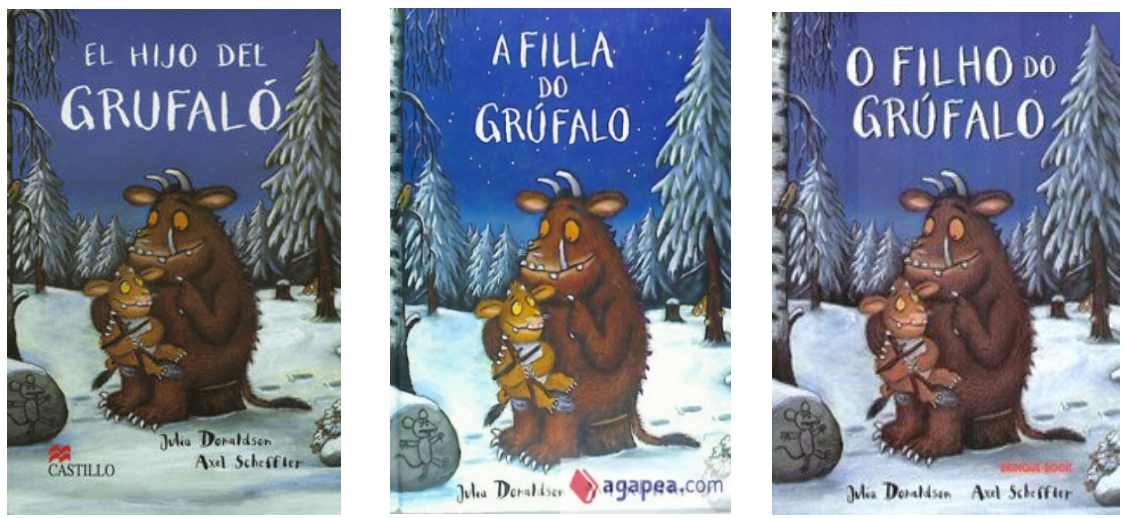

El caso de "A filla do Grúfalo" evidencia lo marcados y sutiles que son muchos roles de género y la importancia que debería tener una reflexión profunda sobre el efecto de los mismos en las primeras lectoras.

Podríamos seguir y comentar cada uno de los veintiún títulos de nuestro catálogo pues detrás de cada uno de ellos hay una reflexión de género (menos en los tres o cuatro primeros, como explicamos antes) que ha ido adquiriendo mayor importancia con cada nuevo proyecto.

La perspectiva feminista se ha convertido para Patasdepeixe en un filtro de calidad cada vez más relevante, hasta llegar a ser un elemento decisivo para publicación, incluso por encima de la calidad de textos o ilustraciones. Muchas personas considerarán que esto es un sinsentido o que altera pilares básicos del concepto mismo de literatura, pero consideramos que cada editorial establece su hoja de ruta y sus prioridades. Para nosotras, como explicamos al comienzo, las prioridades fundacionales eran tres: editar traducciones, editar en lengua galega y ser independientes 
“Transfer” XV: 1-2 (2020), pp. 191-206. ISSN: 1886-554

del gobierno gallego y su sistema insostenible de subvenciones. Ahora mismo, la perspectiva feminista se ha incorporado a esta lista, demostrando así que una editorial es también una entidad viva que cambia y evoluciona con el tiempo.

En este artículo esperamos haber hecho reflexionar sobre el género dentro del catálogo de una editorial y también fuera, en el mundo editorial como sistema y como industria.

En lo referente al catálogo, es muy importante la reflexión sobre el efecto de las primeras lecturas en las personas. Los libros "infantiles" son elementos fundamentales en la construcción del imaginario del mundo para las primeras lectoras/es, y en ellos ven y aprenden la representación del mundo. Nos parece crucial que esa representación, ese código de imágenes refleje un universo de igualdad y sostenibilidad, lo que, hasta ahora, no está pasando. Por ello, las editoras que quieran cambiar el mundo a través de sus libros, deben estar a la altura de dicha responsabilidad a través de sus contenidos.

En cuanto al género dentro del sistema editorial, en este artículo apuntamos de forma intuitiva, gracias a trabajos inéditos como el de Belén López y nuestro breve estudio sobre las cuotas y asignaciones de roles, la necesidad de un cambio estructural profundo en el sector. Aunque existen nuevas pequeñas editoriales creadas después de 2010, como Irmás Cartoné, Catro Ventos, Lata de Sal, Triqueta Verde, etc. dirigidas por mujeres, la industria editorial en Galicia sigue estando mayoritariamente controlada por hombres, tanto en cargos directivos de las principales editoriales y distribuidoras, cargos de representatividad en asociaciones de profesionales y cargos políticos en el ámbito de la cultura y la política lingüística. Sin embargo, el motor de la industria, correctoras, traductoras, lectoras y compradoras de libros es principalmente femenino.

Esperamos que estos pequeños cambios en el sector, la conciencia de género creciente y la aparición de nuevas pequeñas editoras que cuidan y piensan sus productos y contenidos sea el principio de un cambio muy necesario para las lectoras del futuro. 
“Transfer” XV: 1-2 (2020), pp. 191-206. ISSN: 1886-554

\section{Referencias bibliográficas}

AGPTI. (2019). Asociación Galega de Profesionais da Tradución e da Interpretación. En: <<http://www.agpti.org/>>.

AEG. (2019). Asociación de Editoras Galegas. En: $<<$ http://www.editorasgalegas.gal/>>.

BADER, Barbara. (1976). American Picturebooks from Noah'Ark to the Best Within, Nueva York: McMillan.

FUNDACIÓN LUÍS SEOANE. (2018). Programa Galeusca 2018. En: $<<$ https://bit.ly/2DYIZ3W $>>$.

MÉNDEZ, Lourdes. (2007). Antropología feminista. Madrid: Editorial Síntesis.

MORLA, Jorge. (2015). "Un nuevo mundo ilustrado". El País. Suplemento Babel,31/07/2015. En: $<<$ https://bit.ly/2VcOH8f $>>$.

NIKOLAJEVA, M. \& SCOTT, C. (2006). How picturebooks work, Nueva York: Routledge.

SÁEZ, Laura. (2007). "Estudo da viabilidade dun proxecto de creación dunha editora de traducións ao galego para público infantil". Trabajo de DEA (inédito), Universidade de Vigo.

SALISBURY, M. \& STYLES, M. (2012). El arte de ilustrar libros infantiles. Concepto y práctica de la narración visual. Barcelona: Blume.

SEZZI, Annalisa. (2008). "Bridging the Sensorial Gaps: Theory and Practice in Translating the Voice of the Adult Aloud Reader in Pre-School Picturebooks". En: HYDE PARKER, Rebeca \& GUADARRAMA, Karla. (eds.). Thinking Translation, Perspectives from Within and Without, Florida: Brown Walker Press. En: $<<$ https://bit.ly/2VN9Fz5 $>>$.

PENA PRESAS, M. (2018). Feminismos e literatura infantil e xuvenil en Galicia, Santiago de Compostela: Laiovento. 
“Transfer” XV: 1-2 (2020), pp. 191-206. ISSN: 1886-554

\title{
Resumen
}

Este artículo es una aproximación no académica al desarrollo de la editorial Patasdepeixe en su primera década de actividad. Pretendemos analizar su catálogo desde el punto de vista formal y de las autorías, así como encuadrar la editora en el contexto de la industria editorial en Galicia desde una perspectiva feminista.

Palabras clave: Edición, Feminismo, Cuotas, Álbum, Ilustración, Gallego

PATASDEPEIXE PUBLISHING HOUSE: BRIEF ANALYSIS OF THE

CATALOG, EDITION AND TRANSLATION POLICIES FROM A FEMINIST PERSPECTIVE

\begin{abstract}
This article is a non-academic approach to the development of Patasdepeixe publishing house in its first decade of activity. It analyses its catalogue from two main points of view: the formal aspect and the authorship. At the same time, the article tangentially shows the reality of the publishing sector in Galicia in terms of gender and role allocation in order to better understand the current state of this industry
\end{abstract}

Keywords: Publishing, Editing, Feminism, Quota, Illustrated Album, Galician 